\title{
Perkawinan Sasuku dalam Perspektif Hukum Adat di Nagari Sago Salido
}

\author{
Dina Ekawiyani, Nurman S \\ Prodi Pendidikan Pancasila dan Kewarganegaraan \\ FIS Universitas Negeri Padang \\ E-mail: dinaekawiyani@gmail.com
}

\section{ABSTRAK}

Artikel ini bertujuan untuk mengetahui faktor penyebab terjadinya perkawinan sasuku di wilayah Kenagarian Sago Salido Kecamatan IV Jurai Kabupaten Pesisir Selatan. Akibat dari perkawinan sasuku di wilayah ini dan pelaksanaan sanksi adat terhadap pelaku perkawinan sasuku. Hal tersebut dilatarbelakangi oleh faktor saling cinta, faktor hamil diluar nikah dan faktor kurangnya pengetahuan yang menyebabkan perkawinan sasuku terjadi di Wilayah Kenagarian Sago Salido Kecamatan IV Jurai Kabupaten Pesisir Selatan. Metode penelitian dilakukan melalui metode deskriptif dengan pendekatan kualitatif. Informan penelitian adalah Ketua KUA, Ketua KAN, Niniak Mamak, Bundo Kanduang, Pasangan yang melakukan kawin sasuku, Orang tua dari pasangan yang melakukan kawin sasuku, Pemuda-pemudi dan Orang-orang yang tidak melakukan kawin sasuku di Wilayah Kenagarian Sago Salido. Teknik pengumpulan data pada penelitian ini menggunakan teknik wawancara, observasi dan studi dokumentasi. Uji keabsahan data menggunakan teknik triangulasi data. Teknik analisis melalui empat alur yaitu: proses pengumpulan data, reduksi data, penyajian data dan pemeriksaan kesimpulan atau verifikasi.

Kata Kunci: adat, perkawinan sesuku, Pesisir Selatan

\section{ABSTRACT}

This article aims to determine the factors causing the occurrence of sasuku marriage in the Kenagarian Sago Salido region, IV Jurai District, South Pesisir Regency, whether or and the implementation of adat sanctions against the perpetrators of Sasuku marriage in the this region. It is motivated by mutual love, pregnancy factors outside marriage and the lack of knowledge that causes sasuku marriage to occur in Sago Salido. The research method is done through descriptive methods with a qualitative approach. informants of the study are the Chairperson of KUA, Chairperson of KAN, Niniak Mamak, Bundo Kanduang, Couples who have married Sasuku, Parents of couples who have married Sasuku, Youths and People who have not married Sasuku in the Kenagarian Region of Sago Salido. Data collection techniques in this study using interview techniques, observation and documentation studies. Data validity test uses data triangulation techniques. Analysis techniques through four channels, namely: the process of collecting data, reducing data, presenting data and checking conclusions or verification. 
Keywords: indigenous, sesuku marriage, South Coast

\section{PENDAHULUAN}

Perkawinan sasuku adalah perbuatan terlarang di Kenagarian Sago Salido Kecamatan IV Jurai Kabupaten Pesisir Selatan. Meskipun terlarang hal demikian diabaikan, hal ini dilakukan karna aturan adat mengenai perkawinan terlarang tersebut sama sekali tidak diikuti oleh masyarakat. Ini disebabkan karena masyarakat tidak lagi menghargainya yang mana masyarakat tidak lagi menganggapnya sebagai masalah yang penting dan memandang hal ini sebuah mitos.

Perkawinan terlarang yang dilakukan masyarakat di berbagai wilayah Indonesia banyak terjadi. Hal ini telah diteliti oleh Asmaniar dalam jurnal Perkawinan Adat Minangkabau dimana pernikahan sasuku disebut dengan perkawinan pantang dimana perkawinan pantang adalah perkawinan yang akan merusak sistem adat mereka. Yaitu perkawinan orang yang setali darah menurut stelsel matrilineal, sekaum, dan juga sesuku meskipun tidak ada hubungan kekerabatan dan tidak sekampung halaman.

Begitu juga dengan penelitian yang dilakukan oleh ferry Sandy dalam jurnalnya yang berjudul Sanksi Adat Terhadap Perkawinan Sasuku Di Desa Tanjung Kecamatan Koto Kampar Hulu Kabupaten Kampar Berdasarkan Hukum Adat Kampar mengatakan bahwa perkawinan sasuku dilarang karena masyarakat adat desa tanjung memandang perkawinan sasuku adalah perkawinan satu keluarga atau sepersusuan. Artinya masih ada hubungan kekeluargaan atau hubungan darah antar satu dengan yang lainnya.

Sedangkan Menurut Iqbal Sonta Pratama dalam jurnal yang berjudul Peranan Tungku Tigo Sajarangan Dalam Mengatasi Perkawinan Sesuku Menurut Hokum Adat Di Nagari Sungai Buluah Kecamatan Batang Anai Kabupaten Padang Pariaman menulis masyarakat minangkabau merupakan salah satu etnik di Indonesia yang terbesar yang memakai sistem kekerabatan menurut garis keturunan ibu (matrilineal). Perkawinan dalam masyarakat matrilineal sifatnya eksogami. Perkawinan yang terdiri dari dalam kelompok tidak dibenarkan karena mereka semuanya adalah berasal dari satu kelompok yang bertalian darah. Suami tidak masuk kepada kelompok kaum istri dan anak-anaknya dengan perkawinan itu lelaki tetap jadi kaumnya (Iqbal Sonta Pratama, 2017).

Tidak beda hal nya menurut Rahmat Hidayat dalam skripsinya yang berjudul Perkawinan Satu Suku Dalam Masyarakat Minangkabau Menurut Pandangan Hukum Islam Menuliskan Menurut Akmal Sutan Pamuncak menjelaskan bahwa sistem perkawinan di minangkabau ada tiga bentuk yaitu pertama perkawinan 
dilarang ini memberi arti bahwa perkawinan apasaja yang dilarang oleh agama, maka adat juga sepakat dan mengikuti apa yang menjadi larangan dalam agama. Kedua pantangan. Hal ini dimaksudkan dengan perkawinan pantangan yang merupakan perkawinan yang setali darah menurut system matrilineal seperti perkawinan satu suku. Ketiga sumbang, yaitu perkawinan yang tidak dilarang secara tegas oleh hukum adat, tetapi kurang baik menurut hakikat orang minang seperti mengawini dengan dua orang yang bersaudara (bukan saudara kandung atau sedarah) atau kawin dengan orang yang bertetangga (Rahmat Hidayat, 2007).

Begitu juga dengan Menurut Devi Marlina dalam jurnal yang berjudul Larangan Menikah Satu Kaum Dalam Masyarakat Suku Pekal Ditinjau Dari Perspektif Islam mengatakan masyarakat Suku Pekal Kecamatan Malin Deman tidak boleh menikah pada kaum yang sama. Masyarakat Suku Pekal beranggapan bila menikah pada kaum yang sama maka masyarakat suku percaya dan mempunyai keyakinan bahwa pasangan yang melaksanakannya perkawinan tersebut akan mendapat petaka. Petaka yang dimaksud yaitu perkawinan akan banyak cobaan baik adanya perpecahan dalam rumah tangga mereka yang tiada henti dan akan berakhir pada perceraian, yang menimbulkan dampak yang kurang baik pada keturunan-keturunan mereka kelak (Devi Marlina, 2017).

Kemudian hasil penelitian yang dilakukan oleh Nikmah yang berjudul Larangan Perkawinan Satu Suku (Endogami) Di Kota Atambua-Nusa
Tenggara Timur mengatakan bahwa ada tiga sebab larangan mengawini yaitu sebab nasab, hubungan kerabat semenda dengan dan hubungan pertalian susuan. Golongan karena nasab yaitu: ibu anak perempuan, saudara perempuan, bibi dari ayah, bibi dari ibu, keponakan dari saudara laki-laki dan perempuan. Golongan yang haram dikawini karena hubungan semenda yaitu: mertua, menantu, anak tiri (apabila istrinya telah dicampuri), dan dua saudara yang dikawini sekaligus. Sedangkan golongan sepesusuan yaitu: ibu susuan, saudara sepesusuan.

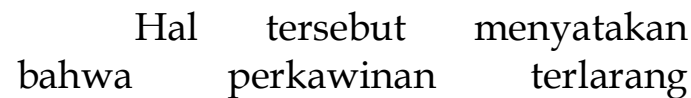
dilakukan di masyarakat Desa Tanjung Kecamatan Koto Kampar Hulu Kabupaten Kampar tidak berbeda dengan masyaraakat Di Kota Atambua-Nusa Tenggara Timur karena mereka juga sering sekali melanggar hukum adat mengenai sebuah perkawinan.

Dari berbagai sumber yang penulis baca dan pahami bahwa perkawinan terlarang yang dilakukan seluruh Indonesia dapat disimpulkan bahwa disebabkan oleh aturan adat yang mana aturan adat tersebut tidak lagi terpakai disebuah masyarakat. Namun demikian berbeda dengan penelitian yang peneliti lakukan di Kenagarian Sago Salido Kecamatan IV Jurai Kabupaten Pesisir Selatan yang mana peraturan ini masih di akui oleh masyarakat namun demikian secara sembunyi-sembunyi orang masih melaksanakannya atas dasar cinta.

Kemudian menurut Saputri dalam jurnal Perkawinan Sasuku Di Desa Tanjung Kecamatan Koto Kampar Hulu Kabupaten Kampar 
mengatakan bahwa kawin sesuku bagi masyarakat desa tanjung Kecamatan Koto Kampar hulu masih tabu dan sangat sacral untuk dilanggar. Mereka yang mencoba kawin sesuku akan mendapatkan konsekuensikonsekuensi yaitu akan ditermajinalkan dari lingkungan keluarga dan menjadi bahan kasakkusuk orang satu kampong, cemoohan dan pengucilan. Orang yang satu suku tidak boleh kawin, sekalipun mereka beda kabupaten atau kota, kecamatan, desa, dusun, selagi mereka dalam satu suku (Melly Dwi Saputri, 2015)

Adapun permasalahan terdapat di Kenagarian Sago Salido Kecamatan IV Jurai Kabupaten Pesisir Selatan yaitu meskipun perkawinan terlarang dilakukan oleh satu suku namun demikian secara diam-diam banyak keluarga yang tetap merestuinya. Jika tidak, pasangan yang akan menikah satu suku ini pergi ke nagari lain untuk melangsungkan pernikahan. Oleh karenanya tulisan ini akan menguraikan 2 permasalahan di Kenagarian Sago Salido Kecamatan IV Jurai Kabupaten Pesisir Selatan. Pertama, masih banyak pelaku kawin sasuku di Kenagarian Sago Salido Kecamatan IV Jurai Kabupaten Pesisir Selatan. Kedua, pemuka adat tidak mampu mencegah terjadinya kawin sasuku di Kenagarian Sago Salido Kecamatan IV Jurai Kabupaten Pesisir Selatan.

Dalam hal ini tujuan penulisan artikel adalah Untuk menganalisis faktor-faktor penyebab terjadinya perkawinan sasuku di wilayah Kenagarian Sago Salido Kecamatan IV Jurai Kabupaten Pesisir Selatan terlaksana atau tidak, untuk menganalisis akibat-akibat terjadinya perkawinan sasuku di Wilayah
Kenagarian Sago Salido Kecamatan IV Jurai Kabupaten Pesisir Selatan. Serta untuk mengidentifikasi pelaksanaan sanksi adat terhadap terjadinya perkawinan sasuku di Wilayah Kenagarian Sago Salido Kecamatan IV Jurai Kabupaten Pesisir Selatan.

\section{METODE PENELITIAN}

Penelitian ini adalah penelitian kualitatif dengan menggunakan metode deskriptif. Penelitian ini dilaksanakan selama lebih kurang tiga bulan. Penelitian dilakukan di Nagari Sago Salido Kecamatan IV Jurai Kabupaten Pesisir Selatan untuk mempermudah peneliti mendapatkan informan yang relevan, disini peneliti memilih purposive sampling

Dalam penelitian ini informan berjumlah 27 orang, penentuan informan yaitu dari responden atau orang-orang yang memberikan informasi seperti Ketua KUA, Ketua KAN, Niniak Mamak, Bundo Kanduang, Pasangan yang melakukan kawin sasuku, Orang tua dari pasangan yang melakukan kawin sasuku, Pemuda-pemuda, Orangorang yang tidak melakukan kawin sasuku di Nagari Sago Salido.

Dengan menggunakan teknik pengumpulan data dengan cara wawancara, observasi dan studi dokumentasi adanya batasan dan ruang lingkup dalam observasi supaya jawabannya tidak melebar. Melalui wawancara informan mengatakan pengetahuan tentang perkawinan sasuku di Nagari Sago Salido. Setelah itu, upaya mendapatkan data yang lebih akurat peneliti melakukan wawancara dengan menggunakan pedoman wawancara. Teknik analisis data yang digunakan adalah display 
data, reduksi data dan penarikan kesimpulan.

\section{HASIL DAN PEMBAHASAN}

Hasil penelitian menunjukkan bahwa masih banyaknya masyarakat di Wilayah Kenagarian Sago Pesisir Selatan yang melakukan perkawinan sasuku bahwa ada 7 pasang orang yang melakukan perkawinan tersebut diantaranya dari berbagai Nagari dan juga berbagai suku agar lebih jelas dapat dilihat di tabel 1.

Tabel 1. Tabel orang yang melakukan perkawinan sasuku

\begin{tabular}{|l|l|l|l|l|}
\hline No & Nagari & Nama Pasangan & Suku & Tahun \\
\hline 1. & Sago (Sianik) & Sial - Eni & Caniago & 2008 \\
\hline 2. & Sago (Karang Sago) & Izul - Ida & Tanjung & 2009 \\
\hline 3. & Salido (Kampung Luar) & Sahar - Rosma & Tanjung & 2010 \\
\hline 4. & Sago (Sianik) & Darto - Eka & Tanjung & 2013 \\
\hline 5. & Sago (Kampung Baru) & Wandi-Nelsi & Caniago & 2013 \\
\hline 6. & Salido (Laban) & Reza -Lina & Jambak & 2016 \\
\hline 7. & Sago (Kampung Baru) & Ali-Roza & Jambak & 2018 \\
\hline
\end{tabular}

Dari tabel di atas tampak bahwa nama-nama pasangan yang melakukan perkawinan sasuku di Kenagarian Sago telah melanggar aturan adat yang berlaku. Hal ini tidak berbeda dari pendapat Menurut Tolib Setiady, S.H., M. Pd, M.H yaitu perkawinan adalah suatu peristiwa yang amat penting dalam peri kehidupan masyarakat kita. Sebab masalah perkawinan itu tidak hanya menyangkut wanita dan pria bakal mempelai saja tetapi juga kedua belah pihak dari orang tua, saudarasaudaranya bahkan keluarga-keluarga mereka masing-masing.

Sedangkan menurut Prof. Dr. Barend Ter Haar, B.Zn. dalam Tolib Setiady, S.H., M.Pd, M.H mengatakan bahwa perkawinan adalah suatu usaha atau peristiwa hukum yang menjaga keberlansungan golongan suatu syarat yang menyebabkan terlahirnya angkatan baru yang meneruskan golongan itu.

Terdapat 3 faktor yang menyebabkan perkawinan sasuku di Wilayah Kenagarian Sago yaitu Faktor saling cinta, hamil diluar nikah dan faktor kurangnya pengetahuan.

1) Faktor saling cinta

Terjadinya pernikahan sesuku karena saling cinta itu merujuk kepada pasangan yang tidak mau mengakhiri hubungannya. Namun faktor cinta juga dapat dikatakan suatu motif yang mana motif merupakan dorongan. Keinginan, hasrat dan tenaga penggerak kainnya yang berasal dari dalam diri manusia, untuk melakukan sesuatu. Semua tingkah laku manusia pada hakikatkan memiliki motif, motif-motif ini memberi tujuan dan arah kepada tingkah laku manusia. Motif timbul karna adanya kebutuhan, kebutuhan dapat dipandang sebagai kekurangan akan suatu hal, dan ini menuntut untuk segera adanya pemenuhannya agar segera mendapat keseimbangan.

\section{2) Faktor hamil diluar nikah}

Sekarang ini, kasus tentang kenakalan remaja semakin marak dan menarik perhatian. Permasalahannya semakin meningkat dan mengkhawatirkan salah satunya adalah kasus penyimpangan seksual yang dilakukan oleh kaum remaja saat ini banyak menimbulkan dampak negatif serta meresahkan masyarakat. Banyak pemberitaan di berbagai media mengatakan tentang permasalahan remaja salah satunya tentang banyaknya permasalahan 
remaja yang mengajukan dispensasi pernikahan yang sebagian besar karena persoalan hamil pernikahan. Hal ini dikarenakan pasangan remaja tersebut masih di bawah umur namun karena terjadi kasus hamil pernikahan, maka mereka harus melakukan pernikahan sehingga harus mengajukan dispensasi pernikahan terlebih dahulu ke pihak pengadilan karena ditolak oleh KUA akibat kurangnya persyaratan pernikahan.

3) Faktor kurangnya pengetahuan Faktor-faktor yang mempengaruhi pengetahuan seseorang yaitu pendidikan, usia, media, informasi. Sedangkan faktorfaktor yang mempengaruhi sikap seseorang yaitu pengalaman pribadi, pengetahuan orang lain, kebudayaan, media, lembaga pendidikan dan faktor emosi.

Berdasarkan hasil penelitian yang peneliti temukan di lapangan diketahui bahwa yang melatarbelakangi pasangan yang melakukan perkwinan satu suku di Kenagarian Sago Salido adalah kurangnya pengetahuan yang dimiliki oleh remaja yang mana remaja sekarang ini banyak tidak mengetahui aturan-aturan adat yang ada di kenagariannya, seperti mereka yang sama suku, mamak kemenakan, dan lain-lainnya (badunsanak). Hal inilah menyebabkan terjadinya perkawinan satu suku.

Dalam hal ini yang termasuk akibat dari orang yang melakukan perkawinan sasuku di Kenagarian Sago Salido adalah berupa sanksi atau denda. Sanksi atau denda berlaku sama terhadap pasangan yang melakukan perkawinan satu suku baik itu yang melakukan perkawinan karena saling cinta, hamil diluar nikah dan atau karena kurangnya pengalaman dari pasangan yang mana sanksi nya adalah di usir dari kampung dan jika tidak pasangan harus membayar denda dengan meminta maaf kepada pemuka adat dan menyemblih satu ekor kerbau untuk di bagikan ke masyarakat yang ada di kampung tersebut.

\section{KESIMPULAN}

Masih banyak pelaku kawin sasuku di Kenagarian Sago Salido Kecamatan IV Jurai Kabupaten Pesisir Selatan disebabkan karena masyarakat menganggap bahwa peraturan yang dibuat oleh adat adalah sebuat mitos yang tidak akan terjadi kebenarannya. Padahal dalam hal ini sudah dilihat langsung oleh masyarakat bahwa orang yang melakukan perkawinan sasuku akan diberi sanksi berupa di usir dari kaum akan tetapi masyarakat masih juga mengabaikan peraturan tersebut.

Dalam hal ini juga dikatakan bahwa pemungka adat tidak mampu mencegah terjadinya kawin sasuku di Kenagarian Sago Salido Kecamatan IV Jurai Kabupaten Pesisir Selatan yang mana sudah bisa dilihat sendiri bahwa pelaku kawin sasuku melakukan segala cara agar dia bisa melangsungkan pernikahan. Misalnya dengan melakukan pernikahan di nagari orang lain supaya pemuka adat tidak mengetahui hal ini, dan juga seperti hamil diluar nikah yang membuat pernikahan harus berlangsung walaupun tidak mendapatkan restu dari orang tua dan juga niniak mamak yang ada. 


\section{DAFTAR PUSTAKA}

Suharsimi. Arikunto. 2016. prosedur penelitian suatu pendekatan praktik. Jakarta: Rineka Cipta.

Asmaniar. 2018 Perkawinan Adat Minangkabau

Marlina, Devi. 2017 Larangan Menikah Satu Kaum Dalam Masyarakat Suku Pekal Ditinjau Dari Perspektif Islam

Sandy, Ferry. 2016 Sanksi adat terhadap perkawinan sesuku di desa tabjung kecamatan koto kampar hulu kabupaten kampar berdasarkan kaum adat kampar. Jurnal JOM fakultas hukum. Vol.I II. No.2. Hal: 1-15.

Pratama, Iqbal Sonta. 2017 Peranan Tungku Tigo Sajarangan Dalam Mengatasi Perkawinan Sesuku Menurut Hokum Adat Di Nagari Sungai Buluah Kecamatan Batang Anai Kabupaten Padang Pariaman

Kurnia, Marry. 2019. Pergumulan adat dan agama (nikah sasuku di minangkabau dalam novel salah pilih karya noer sutan iskandar).

Jurnal.ensiklopediaku.org. vol.1.No.2.Hal:1-7.

Saputri, Melly Dwi. 2015 Perkawinan Sasuku Di Desa Tanjung Kecamatan Koto Kampar Hulu Kabupaten Kampar

Hidayat, Rahmat.2017 dalam skripsinya yang berjudul Perkawinan Satu Suku Dalam Masyarakat Minangkabau Menurut Pandangan Hukum Islam Menuliskan Menurut Akmal Sutan Pamuncak
Nikmah, Roykhatun. 2018 Larangan Perkawinan Satu Suku (Endogami) Di Kota AtambuaNusa Tenggara Timur 